\title{
Two-Stage Biodiesel Synthesis from Used Cooking Oil with a High Acid Value via an Ultrasound-Assisted Method
}

\author{
Ming-Chien Hsiao ${ }^{1,2}$, Wei-Ting Lin ${ }^{1}$, Wei-Cheng Chiu ${ }^{2}$ and Shuhn-Shyurng Hou ${ }^{2,3, *(D)}$ \\ 1 Department of Environmental Engineering, Kun Shan University, Tainan 71070, Taiwan; \\ johnson@mail.ksu.edu.tw (M.-C.H.); r58909082@hotmail.com (W.-T.L.) \\ 2 Green Energy Technology Research Center, Kun Shan University, Tainan 71070, Taiwan; h2owcc@gmail.com \\ 3 Department of Mechanical Engineering, Kun Shan University, Tainan 71070, Taiwan \\ * Correspondence: sshou@mail.ksu.edu.tw; Tel.: +886-6-205-0496
}

\section{check for}

updates

Citation: Hsiao, M.-C.; Lin, W.-T.; Chiu, W.-C.; Hou, S.-S. Two-Stage Biodiesel Synthesis from Used Cooking Oil with a High Acid Value via an Ultrasound-Assisted Method. Energies 2021, 14, 3703. https:// doi.org/10.3390/en14123703

Academic Editors: Stephen D. Prior, Shoou-Jinn Chang, Sheng-Joue Young, Liang-Wen Ji, Hao-Ying Lu and Gianni Bidini

Received: 17 May 2021

Accepted: 18 June 2021

Published: 21 June 2021

Publisher's Note: MDPI stays neutral with regard to jurisdictional claims in published maps and institutional affiliations.

Copyright: (c) 2021 by the authors. Licensee MDPI, Basel, Switzerland. This article is an open access article distributed under the terms and conditions of the Creative Commons Attribution (CC BY) license (https:// creativecommons.org/licenses/by/ $4.0 /)$.
Abstract: In this study, ultrasound was used to accelerate two-stage (esterification-transesterification) catalytic synthesis of biodiesel from used cooking oil, which originally had a high acid value (4.35 mg KOH/g). In the first stage, acid-catalyzed esterification reaction conditions were developed with a 9:1 methanol/oil molar ratio, sulfuric acid dosage at $2 \mathrm{wt} \%$, and a reaction temperature of $60{ }^{\circ} \mathrm{C}$. Under ultrasound irradiation for $40 \mathrm{~min}$, the acid value was effectively decreased from 4.35 to $1.67 \mathrm{mg} \mathrm{KOH} / \mathrm{g}$, which was decreased to a sufficient level ( $<2 \mathrm{mg} \mathrm{KOH} / \mathrm{g}$ ) to avoid the saponification problem for the subsequent transesterification reaction. In the following stage, base-catalyzed transesterification reactions were carried out with a 12:1 methanol/oil molar ratio, a sodium hydroxide dosage of $1 \mathrm{wt} \%$, and a reaction temperature of $65{ }^{\circ} \mathrm{C}$. Under ultrasound-assisted transesterification for $40 \mathrm{~min}$, the conversion rate of biodiesel reached $97.05 \%$, which met the requirement of EN 14214 standard, i.e., $96.5 \%$ minimum. In order to evaluate and explore the improvement of the ultrasound-assisted two-stage (esterification-transesterification) process in shortening the reaction time, additional two-stage biodiesel synthesis experiments using the traditional mechanical stirring method under the optimal conditions were further carried out in this study. It was found that, under the same optimal conditions, using the ultrasound-assisted two-stage process, the total reaction time was significantly reduced to only $80 \mathrm{~min}$, which was much shorter than the total time required by the conventional method of $140 \mathrm{~min}$. It is worth noting that compared with the traditional method without ultrasound, the intensification of the ultrasound-assisted two-stage process significantly shortened the total time from $140 \mathrm{~min}$ to $80 \mathrm{~min}$, which is a reduction of $42.9 \%$. It was concluded that the ultrasound-assisted two-stage (esterification-transesterification) catalytic process is an effective and time-saving method for synthesizing biodiesel from used cooking oil with a high acid value.

Keywords: ultrasound; transesterification; biodiesel; used cooking oil; high free fatty acid; twostage reaction

\section{Introduction}

Biodiesel is a green fuel with low carbon footprint, renewable, sustainable and environmentally friendly characteristics [1,2]. In comparison with conventional petroleum diesel, it has the following advantages: (1) biodiesel is a source of energy, which is renewable and can be produced by bio-process; (2) it is an alternative fuel that can replace petroleum diesel, thereby reducing the demand for imports from abroad; (3) its decomposition yields almost no toxic components, thus helping to reduce environmentally harmful emissions such as greenhouse gases (carbon dioxide), sulfur dioxide, and polycyclic aromatic hydrocarbons; (4) energy crops for the production of biodiesel can be grown on fallow agricultural land, thereby effectively improving the agricultural economy; and (5) for diesel engines, biodiesel has a higher cetane number and better lubricity than petrodiesel [3-5]. High manufacturing costs, among which the price of feedstock is a key factor, are the main difficulty for commercializing biodiesel [6]. To help reduce the total cost, used cooking oil 
(UCO) - which can be easily obtained from restaurants, shops, and families all over the world-can be used as a raw material to replace refined vegetable oil. In terms of saving materials and energy and reducing environmental pollution, this kind of substitution is very helpful to increase the economic value of UCO. As early as 1853, Duffy and Patrick [7] introduced the process of transesterification of vegetable oils into biodiesel. In the chemical transesterification process, triglycerides (such as vegetable oil or UCO) and alcohol are combined with a suitable catalyst to produce biodiesel (alkyl esters) and glycerol.

Many important factors affect the overall reaction efficiency of the transesterification process, including the reaction temperature, reaction time, catalyst loading, catalyst type, and alcohol/oil molar ratio [8-11]. Thus, modifications to the reaction conditions are based primarily on the adjustment of these factors. It has been suggested that with the purpose of accelerating the transesterification process, appropriate catalysts must be added to facilitate and carry out the reaction, and the yield of biodiesel can be improved by adding excess carbon alcohol, usually methanol or ethanol. The use of catalysts can be divided into three cases: acid catalysis, base (alkali) catalysis, and enzyme catalysis. Acid-catalyzed reactions take more time, offer a lower conversion rate, and cause more corrosion of equipment than base-catalyzed reactions. The use of microbial enzymes makes enzyme-catalyzed reactions the most expensive biodiesel manufacturing method. As a result, base-catalyzed reactions are typically preferred [12]. The most common method for current commercial biodiesel manufacturing is base-catalyzed reaction using alkali catalysts with short reaction time, high conversion rate, low cost, etc. Nevertheless, the process needs to consume more energy and causes more difficulties related to recovering waste glycerol and recycling water [13].

In addition to developing catalysts, UCO can replace refined vegetable oil and in turn reduce the feedstock cost of biofuel $[6,14]$. However, usually, UCO has a high FFA content [15-18]. When feedstocks have a high free fatty acid (FFA) content greater than $1.0 \%$, saponification occurs because FFAs cannot be converted into biodiesel [19]. This is a very serious problem since desired products will not be obtained. Therefore, in these cases, the use of acid catalysts, usually sulfuric acid, hydrochloric acid, and phosphoric acid, among others, is a better choice [20]. The transesterification reaction and esterification process may occur simultaneously in acid-catalyzed reaction systems. Hence, acid catalysts can be directly used for the usually much cheaper raw materials with high FFA content (such as UCO and animal fat) [21]. Obviously, when cheap raw materials are used, the total cost of the biodiesel manufacturing process can be reduced. However, the transesterification reaction of UCO with a high acid value using only an acid catalyst usually takes a long time [21].

Compared with the two-stage reaction, the one-stage reaction, the transesterification reaction, has the disadvantages of high catalyst consumption and high alcohol content [22]. In particular, the one-step reaction has the limitation that it is more suitable for raw materials with low FFA content [23]. It is worth noting that a two-stage reaction method has been studied and developed [24-27], which is an effective method for any raw material, especially for overcoming the saponification problem due to high FFA content in the raw material (such as used cooking oil). For high FFA feedstocks with an acid value greater than $2 \mathrm{mg} \mathrm{KOH} / \mathrm{g}$ ), the second stage transesterification is required after the first stage esterification. The purpose of the first stage esterification reaction is to reduce the FFA content in order to become a suitable reactant with low FFA content for the second stage transesterification reaction. According to [28], when using UCO as the feedstock, it is better to use a combined process, that is, a two-step reaction. First, in the pretreatment process, the oil is acid-catalyzed to make the FFA content less than $1.0 \%$; then, the remaining oil is removed, and a solid base catalyst is added for biodiesel synthesis. Consequently, the reaction time is greatly shortened by the use of a two-stage acid-base (alkali) catalyzed method [29]. The two-step reaction includes first step esterification and second step transesterification [30,31]. Obviously, compared with the transesterification 
reaction of UCO with a high acid value using only an acid catalyst, an acid-catalyzed reaction combined with an alkali-catalyzed reaction is more advantageous.

Compared with novel heating methods such as ultrasonic irradiation [29,32], microwave irradiation [6] and radio frequency [33], traditional heating processes require longer reaction times. Among these methods, ultrasound provides an energy source suitable for mass production. Ultrasound is one of the most promising methods to promote biodiesel synthesis reaction, thus replacing the traditional stirred tank reactor [31,34-36]. The sonochemical effect originates from ultrasonic cavitation, which is the key to accelerate the chemical reaction [32]. It helps to improve the mixing of reactants, thereby providing better reaction conditions. When ultrasonic waves are irradiated to the reactants, the collision of the ultrasonic waves with the reactants will cause the generation of microbubbles, resulting in higher local pressure [37]. This process includes the generation, gradual growth and eventual bursting of a series of bubbles through the application of ultrasonic waves to generate a shock wave [38]. The covalent bonds are broken and the mixture becomes homogeneous due to the shock wave energy. As the bubble bursts, energy is released locally and cavitation occurs [32]. Cavitation collapse will locally produce extreme conditions such as high pressure, high temperature, high shear force and turbulence [23]. As a result, it can help produce fine emulsions between immiscible fluids, enhance mass transfer, and thereby increase the rate of transesterification reactions.

As mentioned above, the application of ultrasound in the transesterification of biodiesel has been advocated as a novel technology, which enhances the mass transfer characteristics, thereby shortening the reaction time and possibly reducing the production cost [39]. In addition to the one-stage transesterification process, ultrasonic radiation energy can enhance the two-stage (esterification-transesterification) process in biodiesel production and shorten the reaction time [29]. However, little attention has been paid to the use of ultrasound technology to produce biodiesel using low-quality oil (such as used cooking oil, UCO) with high acid value as a raw material. Especially, as far as we know, biodiesel production from high-acid-value used cooking oil using the two-stage approach of esterification $\left(\mathrm{H}_{2} \mathrm{SO}_{4}\right.$ as a catalyst) followed by transesterification ( $\mathrm{NaOH}$ as a catalyst) incorporated with the ultrasound-assisted method have not yet been reported. Evidently, the novelty of this study is that ultrasound was used to enhance the two-stage (esterification-transesterification) catalyzation process for the synthesis of biodiesel to reduce the reaction time. This article is of interest as it combines the use of a sustainable feedstock to the ultrasound method for biodiesel synthesis. It also emphasizes the use of a two-stage (esterificationtransesterification) catalytic production of biodiesel from used cooking oil with a high acid value via an ultrasound-assisted method.

\section{Materials and Methods}

\subsection{Materials}

Methanol $\left(\mathrm{CH}_{3} \mathrm{OH}\right) 99.8 \%$ and sulfuric acid $\left(\mathrm{H}_{2} \mathrm{SO}_{4}\right) 99 \%$ were obtained from Nippon Shinyaku Co. Ltd., Kyoto, Japan. Sodium hydroxide (NaOH) $98 \%$ was supplied by Mallinckrodt Chemical Ltd., Chesterfield, UK. Acetic acid and methyl laurate were supplied by Honeywell Fluka, New Jersey, USA. UCO samples were provided from fast-food restaurants in Tainan City, Taiwan. Impurities remaining in the UCO sample were carefully filtered. First, to determine the acid value (AV) and saponification value (SV) of UCO, the standard titration method recommended by the American Oil Chemists' Society (AOCS) was employed. Afterwards, the molecular weight (MW) of UCO was calculated using the $\mathrm{AV}$ and SV [6,18]. Table 1 lists the properties (AV, SV, MW) of the UCO.

Table 1. Properties of UCO.

\begin{tabular}{cccc}
\hline Substance & AV $(\mathbf{m g ~ K O H} / \mathbf{g})$ & SV $(\mathbf{m g ~ K O H} / \mathbf{g})$ & Molecular Weight \\
\hline Used cooking oil & 4.35 & 268.1 & 588.36 \\
\hline
\end{tabular}




\subsection{Experimental Procedure}

For the purpose of removing the moisture in the raw material (UCO), first $50 \mathrm{~g}$ of $\mathrm{UCO}$ was put into the flask and heated for $2 \mathrm{~h}$ to $120^{\circ} \mathrm{C}$. Then, the UCO was cooled to $60{ }^{\circ} \mathrm{C}$, and a mixture of catalyst (sulfuric acid) and alcohol (methanol) was added in an appropriate ratio for the esterification reaction in the first stage. The following procedure was carried out for the ultrasonic pre-esterification reaction: mixtures of methanol and UCO were first prepared with various methanol/oil molar ratios (3:1-15:1). Then, $\mathrm{H}_{2} \mathrm{SO}_{4}$ was added into the mixtures at dosage levels ranging from 0.5 to $2.5 \mathrm{wt} \%$. Each reaction system was put into a $250 \mathrm{~mL}$ conical flask, which was maintained at reaction temperatures ranging from 30 to $70{ }^{\circ} \mathrm{C}$ under an ultrasound effect during the reaction time from 10 to $50 \mathrm{~min}$. After the reaction was completed, the mixture was heated at $80^{\circ} \mathrm{C}$ to remove the excess methanol using a rotary evaporator and afterwards cooled to room temperature. Then, using a separating funnel to undergo separation. In order to remove traces of sulfuric acid, the lower layer mixture was removed and washed several times with hot distilled water. For the purpose of removing traces of water, the washed oil was dried in an oven at $105 \pm 3{ }^{\circ} \mathrm{C}$. The objective of the first stage esterification is to reduce the free acid value. Therefore, after washing and drying, the esterified oil was collected and its acid value was measured to monitor the progress of the esterification reaction.

In the second stage of biodiesel synthesis, alkaline transesterification was carried out using esterified oil and base catalyst (sodium hydroxide). For the ultrasonic transesterification process, the mixture had a methanol/oil molar ratio of 3:1 to 15:1, and then 0.2 to $1 \mathrm{wt} \% \mathrm{NaOH}$ was added. The reaction temperature was ranged from 35 to $75^{\circ} \mathrm{C}$ during the reaction time from 10 to $50 \mathrm{~min}$. Again, the reactions were facilitated with ultrasound. At the end of the reaction, the final product has two separate phases: the lighter biodiesel (FAME) in the upper layer and the heavier glycerol in the lower layer. The excess methanol was removed by heating the mixture in a rotary evaporator at $80^{\circ} \mathrm{C}$. Then, the $\mathrm{NaOH}$ catalyst was removed by washing the product with a mixture of $5 \mathrm{wt} \%$ $\mathrm{H}_{3} \mathrm{PO}_{4}$ and water [19]. The traces of water were removed after the washed product was dried in an oven at $105 \pm 3^{\circ} \mathrm{C}$. Finally, the biodiesel samples were measured by using gas chromatography to analyze the conversion rate.

\subsection{Equipment}

The ultrasonic generator (Sonicator 3000, Misonix Inc., Farmingdale, NY, USA) was utilized in this study. It operated at a power of $600 \mathrm{~W}$ and a frequency of $20 \mathrm{kHz}$. In order to carry out the experiment under atmospheric pressure, a $250 \mathrm{~mL}$ spherical glass reactor was modified to introduce cooling water, as shown in Figure 1. A gas chromatography (GC) system (Clarus 600, Perkin Elmer, Inc., Santa Clara, CA, USA) was utilized to analyze the experimental samples [6]. The system includes a capillary column (SPBTM-WAX, $30 \mathrm{~m}$ $\times 0.75 \mathrm{~m} \times 1.0 \mu \mathrm{m}$ ) and a flame ionization detector (FID).

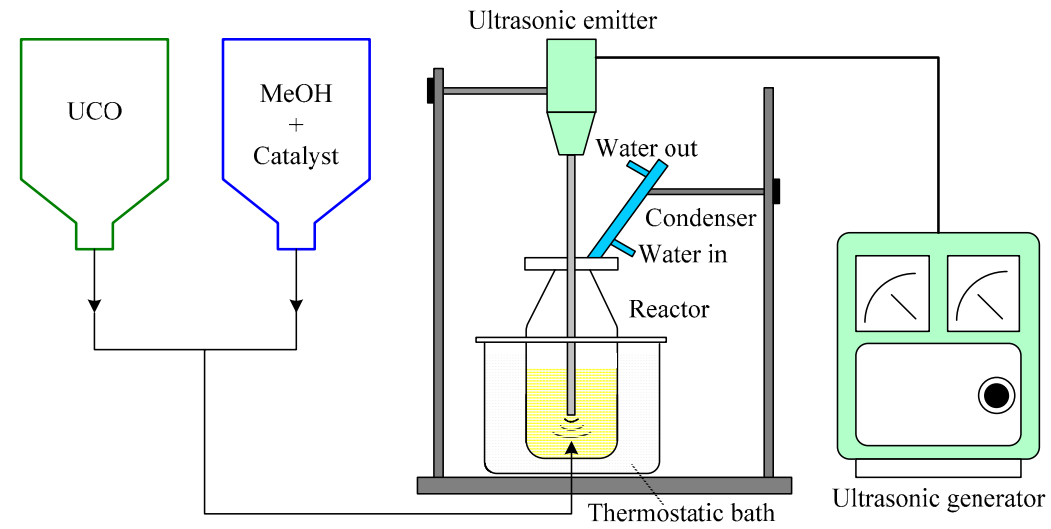

Figure 1. Schematic of the experimental apparatus. 


\subsection{Analytical Methods}

The main purpose of the first stage (esterification reaction) was to reduce the free acid value of the reaction mixture below $2 \mathrm{mg} \mathrm{KOH} / \mathrm{g}$ because of much higher free acid value causing the saponification problem [23]. Thus, in the first stage, the acid-base titration technique was employed to determine the acid value. A standard solution of $0.1 \mathrm{~N} \mathrm{KOH}$ solution and ethanol was utilized to dissolve the sample. $1 \mathrm{~g}$ of used cooking oil was used as a sample, dissolved in ethanol, and heated for 5-10 min. Then phenolphthalein was used as an indicator to titrate a known amount of sample against potassium hydroxide [6].

After the alkaline transesterification reaction in the second stage was completed, a GC analyzer was used for the sample analysis. The sample weight was $0.5 \mathrm{~g}$, including $0.05 \mathrm{~g}$ methyl laurate and $10 \mathrm{~mL}$ hexane as internal standards. The reagents in the sample were thoroughly mixed, and then $1 \mu \mathrm{L}$ of the mixture was injected into the GC analyzer under the following conditions: carrier gas, nitrogen; gas flow rate, $45 \mathrm{~mL} / \mathrm{min}$; split ratio, 1:20; injection temperature, $280^{\circ} \mathrm{C}$, and detector temperature, $300^{\circ} \mathrm{C}$. The oven was first maintained the temperature at $210^{\circ} \mathrm{C}$ for $4 \mathrm{~min}$, and then the temperature was gradually increased at a rate of $4{ }^{\circ} \mathrm{C} / \mathrm{min}$ and finally held at $240{ }^{\circ} \mathrm{C}$ for $8 \mathrm{~min}$. The conversion rate of UCO to FAME (biodiesel) can be calculated using Equation (1) [6] below

$$
\text { Conversion }(\%)=\frac{\left(\frac{\text { area of FAME }}{\text { area of reference }}\right) \times \text { weight of reference }}{\text { weight of crude oil }} .
$$

\section{Results and Discussion}

\subsection{Esterification Reaction in the First Stage}

In the first pretreatment process, acid-catalyzed esterification is aimed to reduce the acid value that necessitates to be below $2 \mathrm{mg} \mathrm{KOH} / \mathrm{g}$ for effectively carrying out transesterification reaction.

\subsubsection{Effect of Methanol/Oil Molar Ratio}

For driving the reversible esterification reaction in forward direction, excess methanol is usually required. Figure 2 shows the variations in the acid value with methanol/oil molar ratio changing from 3:1 to 15:1. The operating conditions were to apply ultrasonic waves within $30 \mathrm{~min}$ to mix the reaction mixture at a constant sulfuric acid concentration of $2 \mathrm{wt} \%$ and a fixed reaction temperature of $50{ }^{\circ} \mathrm{C}$. The original acid value of the UCO sample was $4.35 \mathrm{mg} \mathrm{KOH} / \mathrm{g}$. As can be observed, the acid value gradually decreased as the methanol/oil molar ratio increased from 3:1 to 15:1. When the methanol/oil ratio increased to $9: 1$, the acid value began to fall below $2 \mathrm{mg} \mathrm{KOH} / \mathrm{g}$, i.e., $1.89 \mathrm{mg} \mathrm{KOH} / \mathrm{g}$. With further increase of methanol/oil ratio from 12:1 to 15:1, the acid value was reduced from 1.45 to $1.12 \mathrm{mg} \mathrm{KOH} / \mathrm{g}$. However, a methanol/oil molar ratio of 9:1 is sufficient to reduce the acid value to be less than $2 \mathrm{mg} \mathrm{KOH} / \mathrm{g}$ since further increasing the methanol content would result in excessive waste. Accordingly, the most suitable methanol/oil molar ratio was 9:1. This optimal value of the methanol/oil molar ratio (9:1) is the same as reported in the previous literature (Kashyap et al. [37]). 


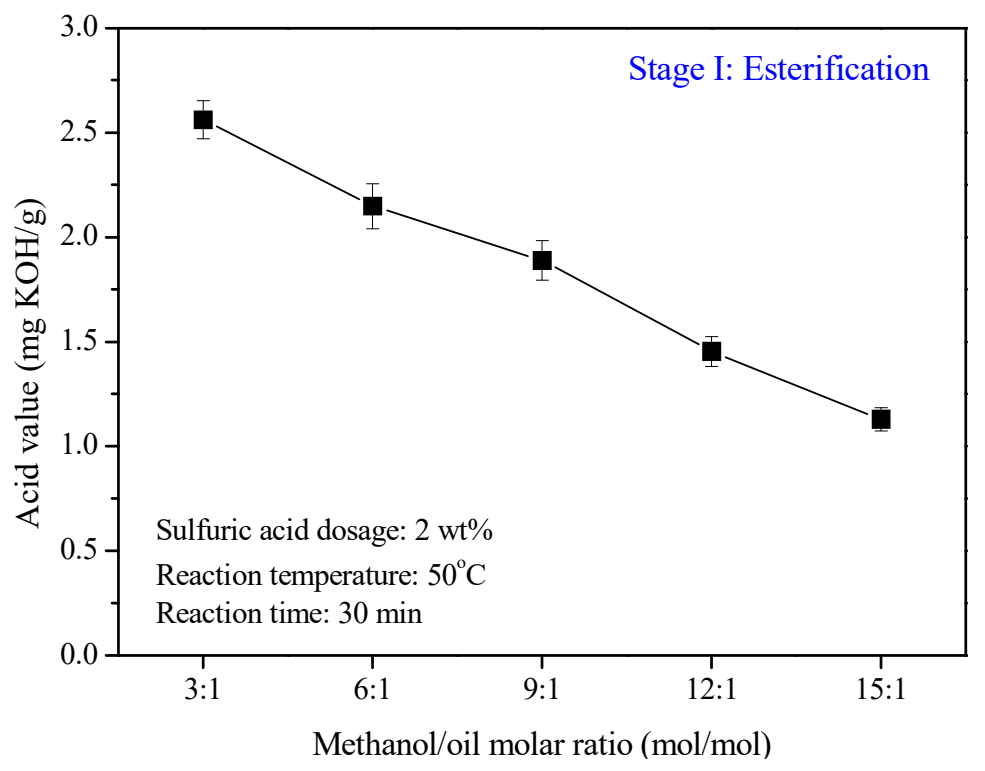

Figure 2. Influence of the methanol/oil molar ratio on the acid value in the first pretreatment process.

\subsubsection{Effect of Catalyst Dosage}

Figure 3 illustrates the effect of the amount of catalyst on the acid value of the first esterification pretreatment process under the experimental operating conditions with a methanol/oil molar ratio of 9:1, a reaction temperature of $50{ }^{\circ} \mathrm{C}$, and a reaction time of $30 \mathrm{~min}$. Sulfuric acid was utilized as a catalyst in the esterification reaction, which not only plays a catalytic role to accelerate the reaction rate, but also acts as a dehydrating agent to force the equilibrium in favor of the ester product. High amount of $\mathrm{H}_{2} \mathrm{SO}_{4}$ can accelerate the esterification reaction to help reduce the acid value of the UCO. It can be seen from Figure 3 that the acid value decreased as the amount of sulfuric acid catalyst increased. As the sulfuric acid amount increased to 2 and $2.5 \mathrm{wt} \%$, the acid value of the UCO after washing reduced to less than $2.0 \mathrm{mg} \mathrm{KOH} / \mathrm{g}$, which was decreased to a sufficient level to avoid the saponification problem for the subsequent transesterification reaction. Thus, $2 \mathrm{wt} \%$ sulfuric acid was found to be the optimal catalyst concentration in the current work, which is consistent with the previous study (Mohod et al. [40]).

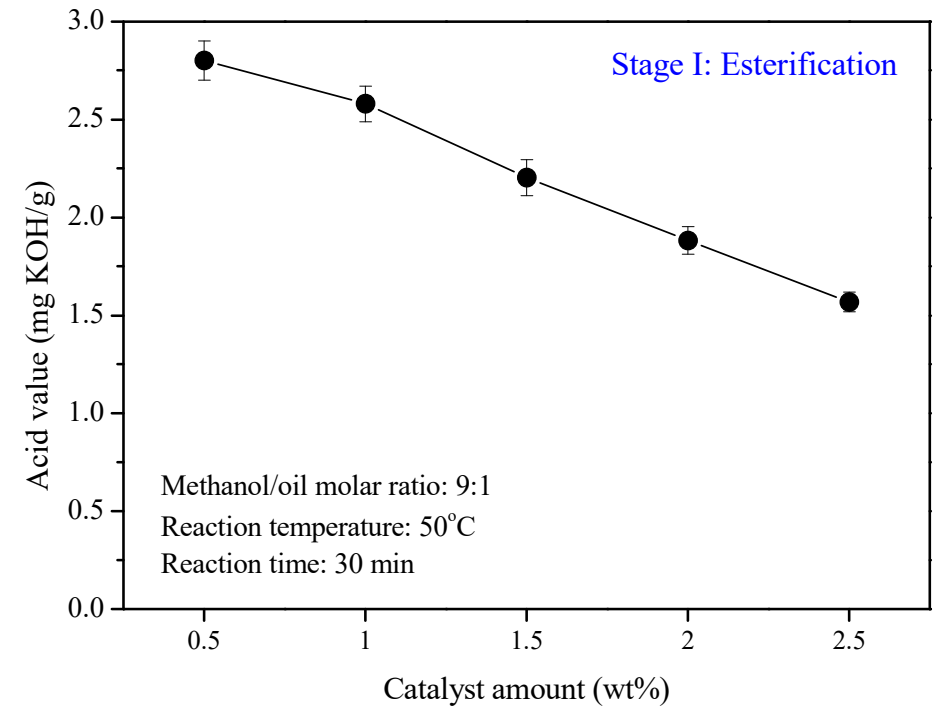

Figure 3. Influence of the catalyst (sulfuric acid) dosage on the acid value in the first pretreatment process. 


\subsubsection{Effect of Reaction Temperature}

The acid value is also influenced by the reaction temperature. This is what can be concluded from Figure 4. The experimental conditions were as follows: a methanol/oil molar ratio 9:1, $2 \mathrm{wt} \%$ sulfuric acid, and a reaction time of $30 \mathrm{~min}$. The reaction temperature was set at several values $\left(30,40,50,60\right.$, and $\left.70^{\circ} \mathrm{C}\right)$. It can be observed that the acid value of the UCO dropped with increases in the reaction temperature. This was because when the reaction temperature increased, the solubility of the methanol in the oil increased; the reaction system became more homogeneous, and the mass transfer resistance between the two phases was reduced. This accelerated the esterification reactions between the FFAs and alcohol. Unfortunately, when the temperature reached about $60^{\circ} \mathrm{C}$, the acid value began to have much slower descent. This was because when the reaction temperature exceeded the boiling point of methanol $\left(64.5^{\circ} \mathrm{C}\right)$, the alcohol evaporated easily from the reaction system, leading to a reduction in the methanol content in the reaction system. The reduction of the acid value was even more insignificant at a higher reaction temperature, e.g., at $70^{\circ} \mathrm{C}$. Also, since the acid value dropped lower than $2 \mathrm{mg} \mathrm{KOH} / \mathrm{g}$ when the reaction temperature was greater than $50{ }^{\circ} \mathrm{C}$-i.e., $60^{\circ} \mathrm{C}$-it was not necessary to use a higher reaction temperature. Thus, in the first esterification pretreatment process, the suitable reaction temperature was $60{ }^{\circ} \mathrm{C}$. This optimal temperature is in agreement with Sadaf et al. [41]. They also reported the same optimal reaction temperature, $60^{\circ} \mathrm{C}$.

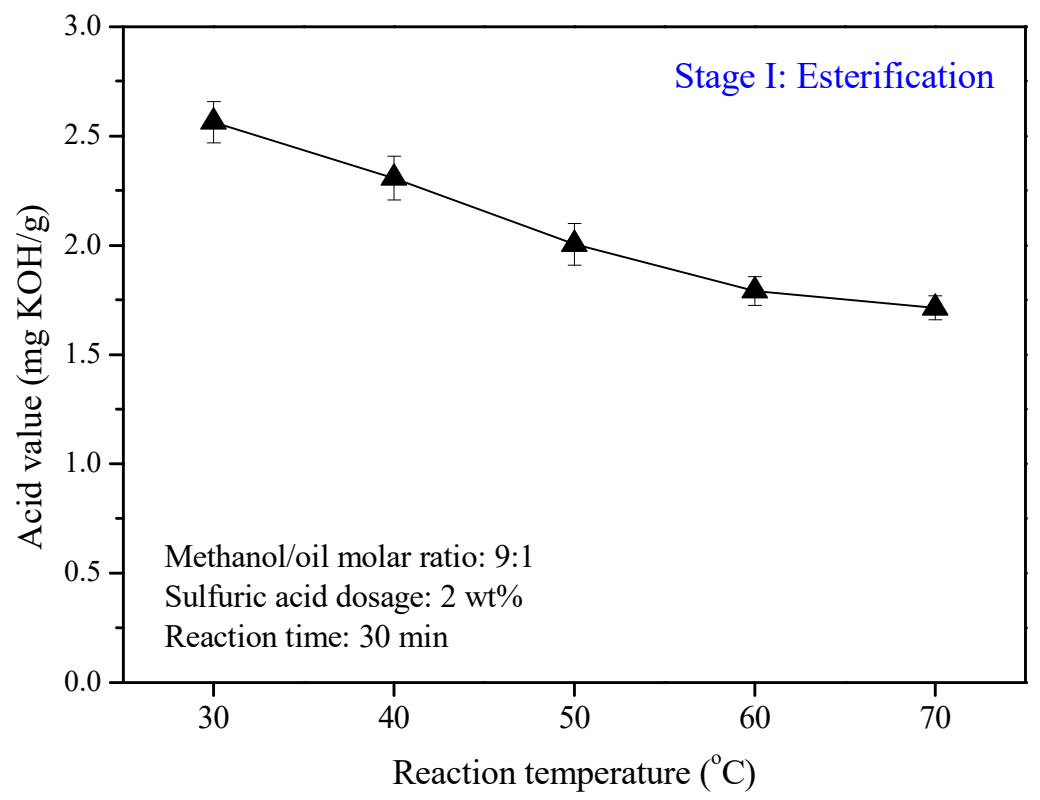

Figure 4. Influence of the reaction temperature on the acid value in the first pretreatment process.

\subsubsection{Effect of Reaction Time}

The acid value of the UCO in the first reaction stage (esterification reaction) also depended on the reaction time. The effect of reaction time on the acid value was investigated under the following conditions: a methanol/oil molar ratio of 9:1, 2 wt \% sulfuric acid, a reaction temperature of $60^{\circ} \mathrm{C}$, and a reaction time ranging from 10 to $50 \mathrm{~min}$. Figure 5 reveals that when the reaction time was longer, a lower acid value was achieved. This was because due to the polarity difference between methanol and oil, which led to poor mixing, the reaction system including intermediate monoglyceride, glycerol, and fatty acids needed time to gradually produce methyl esters. As more esters were formed, the compatibility with methanol increased and thus enhanced the uniformity of the reaction system. These findings are consistent with the reports of $\mathrm{He}$ et al. [27] that initially, as the reaction time increased, the acid value decreased (corresponding to an increase in the esterification rate). When the reaction time reached $40 \mathrm{~min}$, the acid value was reduced to less than $2.0 \mathrm{mg}$ 
$\mathrm{KOH} / \mathrm{g}$ in the present study. Accordingly, a reaction time of $40 \mathrm{~min}$ was deemed to be suitable for the first step of esterification in this work, which is shorter than the optimal time (60 $\mathrm{min})$ reported by He et al. [27].

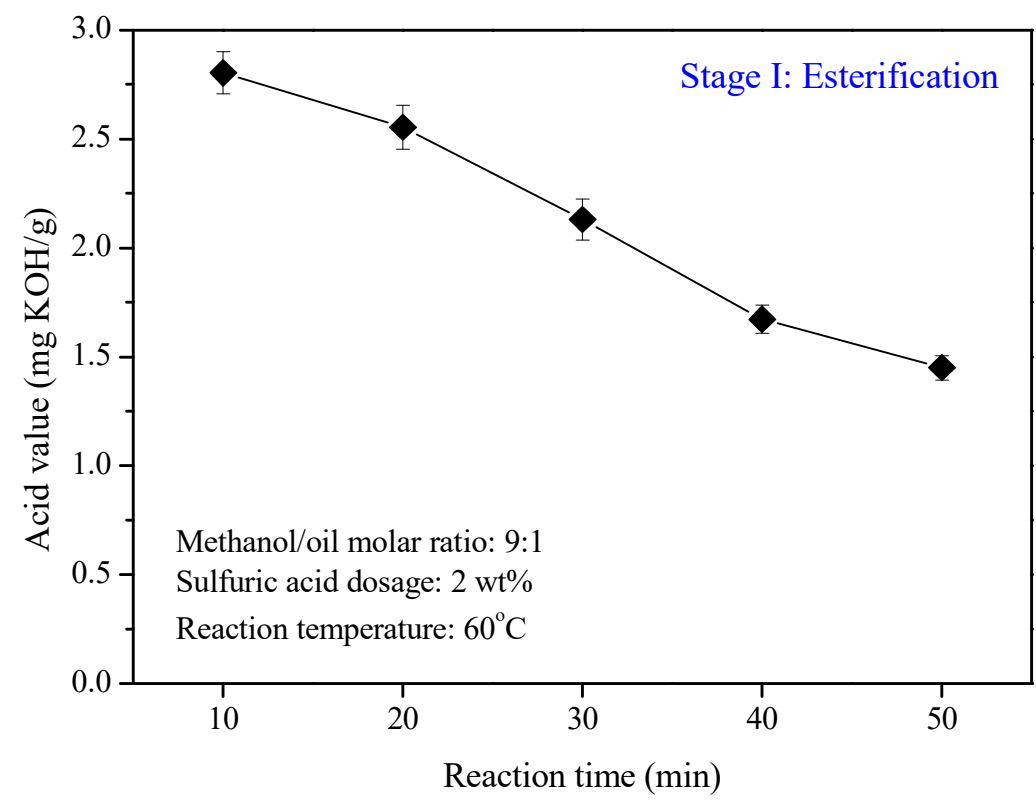

Figure 5. Influence of the reaction time on acid value in the first step of the pretreatment.

\subsection{Transesterification Reaction in the Second Stage}

In the second stage (transesterification reaction), reaction parameters similar to those in the first stage were also studied to examine their impact on biodiesel production.

\subsubsection{Effect of Methanol/Oil Molar Ratio}

As shown in Figure 6, the variation in the conversion rate strongly depended on the methanol/oil molar ratio. At this stage, ultrasound was also used to assist the transesterification reaction. In order to examine the effect of methanol/oil molar ratio on the acid value, the methanol/oil molar ratio were set from 3:1 to 15:1, and the sodium hydroxide dosage, reaction temperature and reaction time were set at $1 \mathrm{wt} \%, 65^{\circ} \mathrm{C}$ and $30 \mathrm{~min}$, respectively. The results showed that when the molar ratio was 3:1, the conversion rate was low because there was not enough methanol to mix with the oil effectively. Therefore, the conversion rate was only around $35.36 \%$. As more methanol was added, the reaction shifted the equilibrium towards a favorable direction to the product side, which in turn increased the conversion rate. At a molar ratio of $12: 1$, the conversion rate reached $97.05 \%$, which was an acceptable value according to the EN-14214 standard. Also, when the molar ratio was $15: 1$, the conversion rate was only $97.37 \%$, which was only $0.32 \%$ higher; thus, raising the molar ratio incrementally to more than 12:1 was not worth the cost of the excess amount of methanol. These trends regarding the influence of molar ratio on the conversion rate are similar to those of Hsiao et al. [18] and He et al. [27]. Based on the cost considerations, the alcohol to be added to the oil was suitable at a molar ratio of 12:1, which is the same as the optimal molar ratio found in Hsiao et al.'s study [18]. 


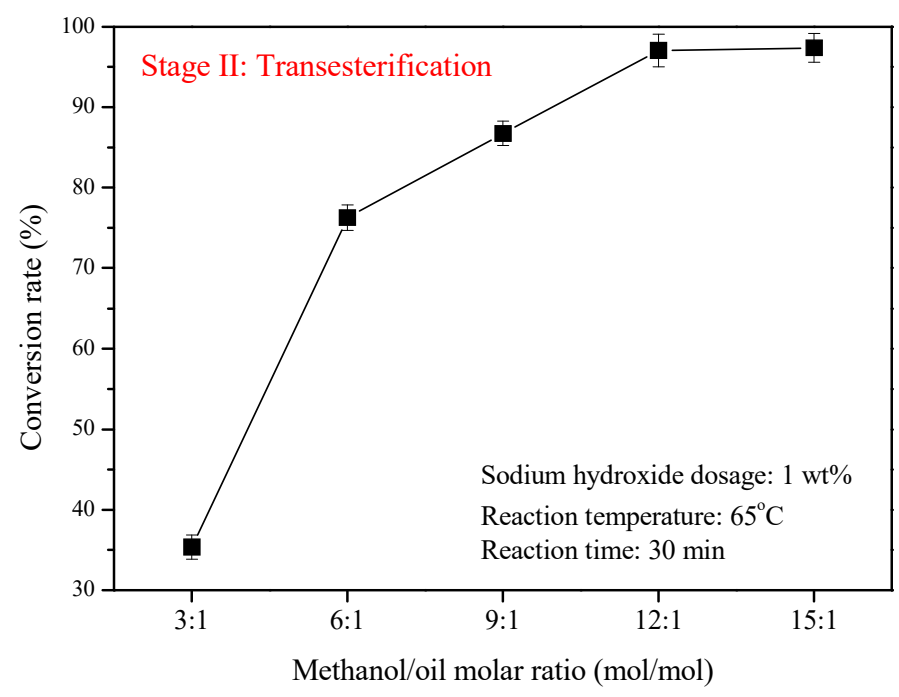

Figure 6. Influence of the methanol/oil molar ratio on the conversion rate.

\subsubsection{Effect of Catalyst Dosage}

Figure 7 shows the changes in the conversion rate with respect to the change in the catalyst dosage. Alkali metal oxides and hydroxides, especially sodium hydroxide, are efficient and economic catalysts in the transesterification process. In this experiment, the amount of sodium hydroxide catalyst was set to range from 0.2 to $1.0 \mathrm{wt} \%$, with a methanol/oil molar ratio of $12: 1$, and a reaction temperature of $65^{\circ} \mathrm{C}$. It was found that, after the same reaction duration (30 $\mathrm{min})$, the conversion rate did reach $97 \%$ when the amount of sodium hydroxide catalyst was $1 \mathrm{wt} \%$. When the amount of catalyst exceeded $1.0 \mathrm{wt} \%$, the conversion rate did not increase significantly. This was because when too much alkali was used, there was a stronger saponification reaction, which caused a small amount of biodiesel to be blocked in the gel material, and the reaction time required for the generation of colloidal substances increased. The viscosity of the reaction system increased, and it even eventually became a gel. This resulted in more difficulty in the final product separation process (biodiesel purification), where more water was required for the washing steps, thus creating more waste water. Thus, the optimal alkali catalyst dosage should be $1 \mathrm{wt} \%$. Similar results were reported in the previous study [18], where the optimal $\mathrm{NaOH}$ catalyst concentration was in the range of 0.8 to $1.0 \mathrm{wt} \%$.

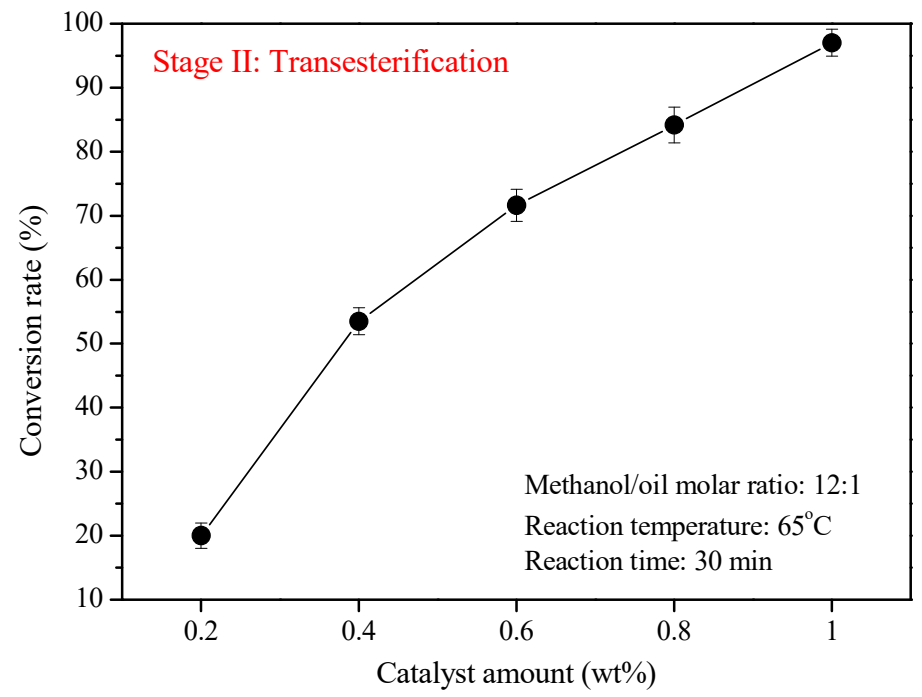

Figure 7. Influence of the catalyst amount on the conversion rate. 


\subsubsection{Effect of Reaction Temperature}

The influence of the reaction temperature on the conversion rate was studied under the following reaction conditions: a methanol/oil molar ratio of 12:1, a sodium hydroxide dosage of $1 \mathrm{wt} \%$, a reaction time of $30 \mathrm{~min}$, and reaction temperature ranging from 35 to $75^{\circ} \mathrm{C}$. Figure 8 shows the proportional dependence between the two values within the temperature ranged from 35 to $65^{\circ} \mathrm{C}$. However, when the temperature exceeded the methanol boiling point of $64.5^{\circ} \mathrm{C}$, the conversion rate began to decrease from its highest value. This decrement was even greater when the temperature reached $75{ }^{\circ} \mathrm{C}$ because when the temperature was farther from the $64.5^{\circ} \mathrm{C}$ boiling point of methanol, the methanol evaporated more quickly. This lowered the methanol content in the reaction system and led to the decline in the reaction conversion rate. Therefore, the reaction temperature must be chosen appropriately to increase the reaction rate and enhance the conversion rate. In the second stage, the suitable reaction temperature was $65^{\circ} \mathrm{C}$, which is consistent with Hsiao et al.'s work [18].

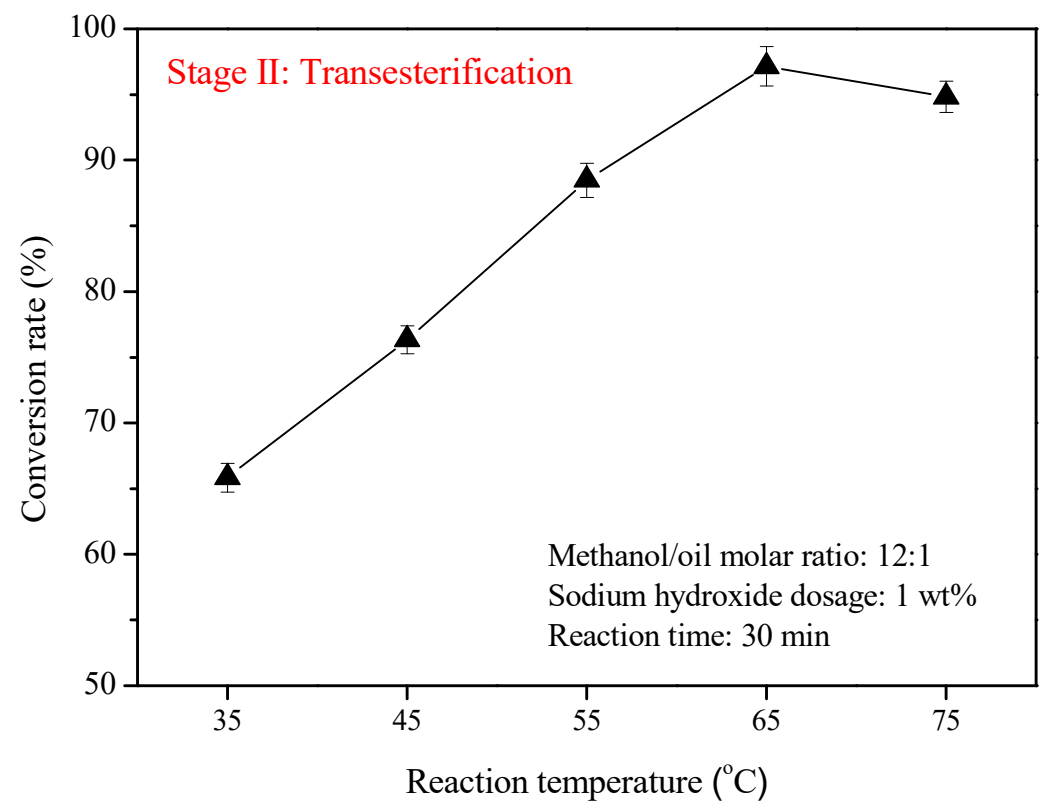

Figure 8. I Influence of the reaction temperature on the conversion rate.

\subsubsection{Effect of Reaction Time}

A longer reaction time led to a higher conversion rate. However, although the conversion rate increased rapidly for the first $30 \mathrm{~min}$, from $53.50 \%$ up to almost $95 \%$, it did not increase significantly within the next $20 \mathrm{~min}$, as shown in Figure 9. According to the transesterification reaction mechanism, it is a reversible reaction. Thus, after a certain period, the reaction reached its equilibrium, and further extension of the time did not lead to any significant increase in the conversion rate. With the help of ultrasound under the following operating conditions: a methanol/oil molar ratio of 12:1, a $1 \mathrm{wt} \%$ catalyst, and a reaction temperature of $65{ }^{\circ} \mathrm{C}$, the conversion rate did reach $97.05 \%$ (higher than the standard specification for biodiesel based on EN 14214) after $40 \mathrm{~min}$, and it did not increase significantly more over time. Therefore, a reaction time of $40 \mathrm{~min}$ was considered sufficient to obtain the desired conversion rate. Additionally, the conversion rate reached $97.05 \%$, which complied with the European Standard EN 14214. Notably, in the second stage of transesterification, the optimal reaction time obtained in this study was $40 \mathrm{~min}$, which was slightly shorter than the 50 min obtained in Sadaf et al.'s study [41]. 


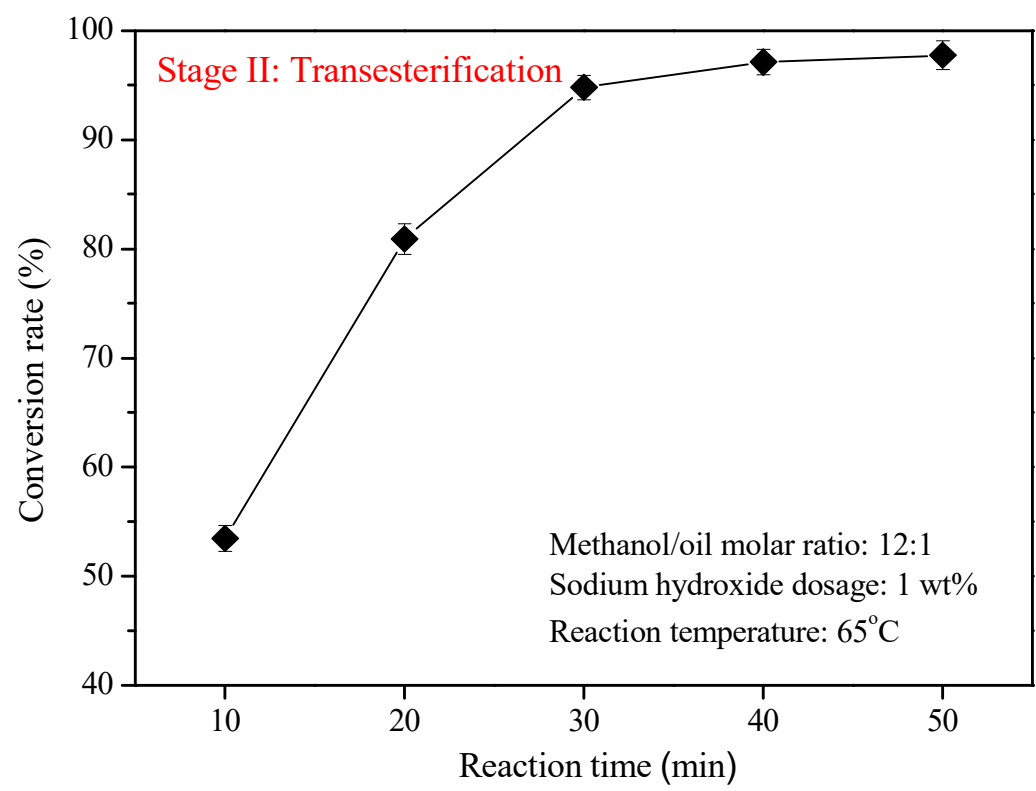

Figure 9. Influence of the reaction time on the conversion rate.

\subsection{Comparison between Conventional and Ultrasonic Methods under Optimal Conditions}

In the present study, in order to further evaluate and explore the improvement of the ultrasound-assisted two-stage (esterification-transesterification) process in shortening the reaction time, additional experiments were carried out using the traditional mechanical stirring method under the same optimized conditions. The optimal operating parameters for the first stage (esterification) and the second stage (transesterification)-including methanol/oil molar ratio, catalyst concentration, and reaction temperature-can be obtained from Sections 3.1 and 3.2, respectively.

Table 2 shows the comparison of reaction time between conventional and ultrasonic methods under optimal conditions. Comparing the results of using the conventional and ultrasound-assisted methods, it is obvious that the ultrasound-assisted method has shown a significant improvement in shortening the reaction time. In the first stage, $\mathrm{H}_{2} \mathrm{SO}_{4}$ was utilized as a catalyst for esterification reaction. As shown in Table 2, in order to reduce the acid value of $\mathrm{UCO}$ to less than $2 \mathrm{mg} \mathrm{KOH} / \mathrm{g}$ via acid-esterification reaction, the conventional method requires $60 \mathrm{~min}$, while the ultrasonic method only requires $40 \mathrm{~min}$. In the second stage, the product (esterified oil) of the first stage was used as a reactant and $\mathrm{NaOH}$ was employed as a catalyst for transesterification reaction. The FAME conversion rate must meet the requirement of EN 14214 standard, i.e., $96.5 \%$ minimum. In order to comply with the requirement of $96.5 \%$ conversion rate, Table 2 also shows that the transesterification reaction time required by the traditional method and the ultrasoundassisted method were 80 and $40 \mathrm{~min}$, respectively. Using the same two-stage (esterificationtransesterification) process under the optimal conditions, the use of ultrasound-assisted technology significantly reduced the total reaction time to only $80 \mathrm{~min}$ compared with the conventional method that required a total reaction time of $140 \mathrm{~min}$. It is noteworthy that compared with the traditional method for biodiesel production without ultrasound, the improvement of this two-stage (esterification-transesterification) process assisted by ultrasonication significantly reduced the total time by $42.9 \%$.

In addition, it is worth noting that the total time was significantly reduced to only $80 \mathrm{~min}$ for the entire two-stage (esterification-transesterification) catalyzed process in the present study. Compared with the 120-min conventional transesterification reaction using a two-stage catalytic process but a magnetically stirred reactor reported by Charoenchaitrakool and Thienmethangkoon [42], this ultrasound-assisted two-stage biodiesel production method saved a substantial amount of time; specifically, the total reaction 
time of this work is only two-thirds of the traditional method [42]. More recently, Sadaf et al. [41] reported a two-stage process, which required $250 \mathrm{~min}$ of total reaction time under optimal conditions using the conventional method. Therefore, it is also confirmed that, compared with the traditional method [41], under the same two-stage process conditions, the ultrasound-assisted synthesis method used in the current work has a significant improvement in shortening the reaction time, that is, the total reaction time is greatly reduced by $68 \%$. The key intensification parameter is ultrasonication, which can generate cavitation collapse to help produce fine emulsions between immiscible liquids, enhance mass transfer caused by large interfacial area, and thereby increase the rate of transesterification reactions $[23,42]$.

Table 2. Comparison of reaction time between conventional and ultrasonic methods under optimal conditions.

\begin{tabular}{ccccc}
\hline Parameter & \multicolumn{2}{c}{ Conventional Method } & \multicolumn{2}{c}{ Ultrasonic Method } \\
\cline { 2 - 5 } & $\mathbf{E}$ & $\mathbf{T}$ & $\mathbf{E}$ & $\mathbf{T}$ \\
\hline Reaction time (min) & 60 & 80 & 40 & 40 \\
Molar ratio & $1: 9$ & $1: 12$ & $1: 9$ & $1: 12$ \\
Catalyst type & $\mathrm{H}_{2} \mathrm{SO}_{4}$ & $\mathrm{NaOH}$ & $\mathrm{H}_{2} \mathrm{SO}_{4}$ & $\mathrm{NaOH}$ \\
Catalyst concentration $(\mathrm{wt} \%)$ & 2 & 1 & 2 & 1 \\
Reaction temperature $\left({ }^{\circ} \mathrm{C}\right)$ & 60 & 65 & 60 & 65 \\
\hline
\end{tabular}

E: Esterification; T: Transesterification.

\section{Conclusions}

In order to evaluate the beneficial effects of ultrasound on the transesterification process and determine the most suitable reaction conditions, a two-stage catalytic reaction process promoted using ultrasound was studied to produce biodiesel from used cooking oil. In the first stage of the acid-catalyzed reaction, the optimal reaction conditions were as follows: a methanol/oil molar ratio of 9:1, $2 \mathrm{wt} \%$ sulfuric acid, and a reaction temperature of $60^{\circ} \mathrm{C}$. Ultrasound helped to effectively reduce the acid value to less than $2 \mathrm{mg} \mathrm{KOH} / \mathrm{g}$ within $40 \mathrm{~min}$. The main product (esterified oil) of the first stage was then moved to the second stage for base-catalyzed reaction, which was carried out under ultrasonic irradiation under the following optimal reaction conditions: a methanol/oil molar ratio of 12:1, $1 \mathrm{wt} \%$ sodium hydroxide, a reaction temperature of $65^{\circ} \mathrm{C}$, and reaction time of $40 \mathrm{~min}$. After a total of $80 \mathrm{~min}$ during the two-stage esterification-transesterification reaction, the conversion rate reached $97.05 \%$, which was higher than the required standard specification ( $96.5 \%$ minimum, European Standard EN 14214) for the biodiesel manufacturing process. For comparison, under the same optimal conditions as the ultrasound-assisted method, this study also used the traditional mechanical stirring method for the two-stage (esterificationtransesterification) biodiesel synthesis. It is worth noting that, compared with the conventional method requiring a total reaction time of $140 \mathrm{~min}$, the use of ultrasound-assisted methods significantly reduced the total reaction time to only $80 \mathrm{~min}$, which greatly reduced the total time by $42.9 \%$.

Ultrasound technology has great potential for building pilot scale ultrasound-assisted biodiesel reactors. However, there are few pilot-scale demonstrations of ultrasound-assisted biodiesel production. In the future, a pilot plant will be designed and constructed to produce biodiesel from used cooking oil. Therefore, a two-step process of biodiesel synthesis using used cooking oil as a raw material will be further studied in the pilot plant.

Author Contributions: All authors (M.-C.H., W.-T.L., W.-C.C., and S.-S.H.) made equal contributions to this study, which include acquisition and interpretation of data, analysis of the results, and preparation of the manuscript. In addition, S.-S.H. made a special contribution in the writing and editing of the manuscript. All authors have read and agreed to the published version of the manuscript. 
Funding: This work was supported by the Ministry of Science and Technology, Taiwan under grant no. MOST 108-2637-E-168-010.

Institutional Review Board Statement: Not applicable.

Informed Consent Statement: Not applicable.

Conflicts of Interest: The authors declare no conflict of interest.

\section{References}

1. Lin, C.Y.; Lu, C. Development perspectives of promising lignocellulose feedstocks for production of advanced generation biofuels: A review. Renew. Sust. Energ. Rev. 2021, 136, 110445. [CrossRef]

2. Wong, W.Y.; Lim, S.; Pang, Y.L.; Shuit, S.H.; Chen, W.H.; Lee, K.T. Synthesis of renewable heterogeneous acid catalyst from oil palm empty fruit bunch for glycerol-free biodiesel production. Sci. Total Environ. 2020, 727, 138534. [CrossRef] [PubMed]

3. Shan, R.; Lu, L.; Shi, Y.; Yuan, H.; Shi, J. Catalysts from renewable resources for biodiesel production. Energy Convers. Manag. 2018, 178, 277-289. [CrossRef]

4. Ma, X.; Liu, F.; Helian, Y.; Li, C.; Wu, Z.; Li, H.; Chu, H.; Wang, Y.; Wang, Y.; Lu, W.; et al. Current application of MOFs based heterogeneous catalysts in catalyzing transesterification/esterification for biodiesel production: A review. Energy Convers. Manag. 2021, 229, 113760. [CrossRef]

5. Yaqoob, H.; Teoh, Y.H.; Sher, F.; Farooq, M.U.; Jamil, M.A.; Kausar, Z.; Sabah, N.U.; Shah, M.F.; Rehman, H.Z.U.; Rehman, A.U. Potential of waste cooking oil biodiesel as renewable fuel in combustion engines: A Review. Energies 2021, 14, 2565. [CrossRef]

6. Hsiao, M.C.; Kuo, J.Y.; Hsieh, S.A.; Hsieh, P.H.; Hou, S.S. Optimized conversion of waste cooking oil to biodiesel using modified calcium oxide as catalyst via a microwave heating system. Fuel 2020, 266, 117114. [CrossRef]

7. El Alaoui, M. Fuzzy goal programming for biodiesel production. Int. J. Green Energy 2020, 17, 644-651. [CrossRef]

8. Raheem, I.; Mohiddin, M.N.B.; Tan, Y.H.; Kansedo, J.; Mubarak, N.M.; Abdullah, M.O.; Ibrahim, M.L. A review on influence of reactor technologies and kinetic studies for biodiesel application. Ind. Eng. Chem. Res. 2020, 91, 54-68. [CrossRef]

9. Kumar, S.A.; Sakthinathan, G.; Vignesh, R.; Banu, J.R.; Ala'a, H. Optimized transesterification reaction for efficient biodiesel production using Indian oil sardine fish as feedstock. Fuel 2019, 253, 921-929. [CrossRef]

10. Rezania, S.; Oryani, B.; Park, J.; Hashemi, B.; Yadav, K.K.; Kwon, E.E.; Hur, J.; Cho, J. Review on transesterification of non-edible sources for biodiesel production with a focus on economic aspects, fuel properties and by-product applications. Energy Convers. Manag. 2019, 201, 112155. [CrossRef]

11. Sundaramahalingam, M.A.; Karthikumar, S.; Kumar, R.S.; Samuel, K.J.; Shajahan, S.; Sivasubramanian, V.; Sivashanmugam, P.; Varalakshmi, P.; Syed, A.; Marraiki, N.; et al. An intensified approach for transesterification of biodiesel from Annona squamosa seed oil using ultrasound-assisted homogeneous catalysis reaction and its process optimization. Fuel 2021, 291, 120195. [CrossRef]

12. Ganesan, R.; Manigandan, S.; Samuel, M.S.; Shanmuganathan, R.; Brindhadevi, K.; Chi, N.T.L.; Chi, P.A.; Pugazhendhi, A. A review on prospective production of biofuel from microalgae. Biotechnol. Rep. 2020, 27, e00509. [CrossRef]

13. Nomanbhay, S.; Ong, M.Y. A review of microwave-assisted reactions for biodiesel production. Bioengineering 2017, 4, 57. [CrossRef]

14. Mohadesi, M.; Aghel, B.; Maleki, M.; Ansari, A. The use of $\mathrm{KOH} /$ clinoptilolite catalyst in pilot of microreactor for biodiesel production from waste cooking oil. Fuel 2020, 263, 116659. [CrossRef]

15. Hsiao, M.C.; Kuo, J.Y.; Hsieh, P.H.; Hou, S.S. Improving biodiesel conversions from blends of high-and low-acid-value waste cooking oils using sodium methoxide as a catalyst based on a high speed homogenizer. Energies 2018, 11, 2298. [CrossRef]

16. Hsiao, M.C.; Hou, S.S.; Kuo, J.Y.; Hsieh, P.H. Optimized conversion of waste cooking oil to biodiesel using calcium methoxide as catalyst under homogenizer system conditions. Energies 2018, 11, 2622. [CrossRef]

17. Hsiao, M.C.; Chang, L.W.; Hou, S.S. Study of solid calcium diglyceroxide for biodiesel production from waste cooking oil using a high speed homogenizer. Energies 2019, 12, 3205. [CrossRef]

18. Hsiao, M.C.; Liao, P.H.; Lan, N.V.; Hou, S.S. Enhancement of biodiesel production from high-acid-value waste cooking oil via a microwave reactor using a homogeneous alkaline catalyst. Energies 2021, 14, 437. [CrossRef]

19. Gole, V.L.; Gogate, P.R. Intensification of synthesis of biodiesel from non-edible oil using sequential combination of microwave and ultrasound. Fuel Process. Technol. 2013, 106, 62-69. [CrossRef]

20. Thangaraj, B.; Solomon, P.R.; Muniyandi, B.; Ranganathan, S.; Lin, L. Catalysis in biodiesel production- a review. Clean Energy 2019, 3, 2-23. [CrossRef]

21. Suraj, C.K.; Anand, K.; Sundararajan, T. Investigation of biodiesel production methods by altering free fatty acid content in vegetable oils. Biofuels 2017, 1, 587-595. [CrossRef]

22. Thoai, D.N.; Tongurai, C.; Prasertsit, K.; Kumar, A. Review on biodiesel production by two-step catalytic conversion. Biocatal. Agric. Biotechnol. 2019, 18, 101023. [CrossRef]

23. Seithtanabutara, V.; Sungnat, C.; Wongwuttanasatian, T. Comparison of free fatty acid conversion yields for esterification assisted by single-and dual-frequency sonication. Biomass Convers. Bior. 2020, 10, 1-13. [CrossRef]

24. Kirubakaran, M.; Selvan, V.A.M. Egg shell as heterogeneous catalyst for synthesis of biodiesel from high free fatty acid chicken fat and its working characteristics on a CI engine. J. Environ. Chem. Eng. 2018, 6, 4490-4503. 
25. Banerjee, N.; Barman, S.; Saha, G.; Jash, T. Optimization of process parameters of biodiesel production from different kinds of feedstock. Mater. Today 2018, 5, 23043-23050. [CrossRef]

26. Keskin, A. Two-step methyl ester production and characterization from the broiler rendering fat: The optimization of the first step. Renew. Energy 2018, 122, 216-224. [CrossRef]

27. He, C.; Mei, Y.; Zhang, Y.; Liu, L.; Li, P.; Zhang, Z.; Jing, Y.; Li, G.; Jiao, Y. Enhanced biodiesel production from diseased swine fat by ultrasound-assisted two-step catalyzed process. Bioresour. Technol. 2020, 304, 123017. [CrossRef]

28. Kasirajan, R. Biodiesel Production by two step process from an energy source of chrysophyllum albidum oil using homogeneous catalyst. S. Afr. J. Chem. Eng. 2021, 37, 161-166.

29. Suresh, T.; Sivarajasekar, N.; Balasubramani, K. Enhanced ultrasonic assisted biodiesel production from meat industry waste (pig tallow) using green copper oxide nanocatalyst: Comparison of response surface and neural network modelling. Renew. Energy 2021, 164, 897-907. [CrossRef]

30. Suwannapa, P.; Tippayawong, N. Optimization of two-step biodiesel production from beef tallow with microwave heating. Chem. Eng. Commun. 2017, 204, 618-624. [CrossRef]

31. Haghighi, S.F.M.; Parvasi, P.; Jokar, S.M.; Basile, A. Investigating the effects of ultrasonic frequency and membrane technology on biodiesel production from chicken waste. Energies 2021, 14, 2133. [CrossRef]

32. Carmona-Cabello, M.; Sáez-Bastante, J.; Pinzi, S.; Dorado, M.P. Optimization of solid food waste oil biodiesel by ultrasoundassisted transesterification. Fuel 2019, 255, 115817. [CrossRef]

33. Ma, Y.; Liu, S.; Wang, Y.; Adhikari, S.; Dempster, T.A.; Wang, Y. Direct biodiesel production from wet microalgae assisted by radio frequency heating. Fuel 2019, 256, 115994. [CrossRef]

34. Chuah, L.F.; Klemes, J.J.; Yusup, S.; Bokhari, A.; Akbar, M.M. A review of cleaner intensification technologies in biodiesel production. J. Clean. Prod. 2017, 146, 181-193. [CrossRef]

35. Gholami, A.; Pourfayaz, F.; Maleki, A. Techno-economic assessment of biodiesel production from canola oil through ultrasonic cavitation. Energy Rep. 2021, 7, 266-277. [CrossRef]

36. Topare, N.S.; Patil, K.D.; Khedkar, S.V. Effects of operating parameters on biodiesel production from waste cooking oil under ultrasonic irradiation. Mater. Today Proc. 2021, in press.

37. Kashyap, S.S.; Gogate, P.R.; Joshi, S.M. Ultrasound assisted synthesis of biodiesel from karanja oil by interesterification: Intensification studies and optimization using RSM. Ultrason. Sonochem. 2019, 50, 36-45. [CrossRef]

38. Tavares, G.R.; Gonçalves, J.E.; dos Santos, W.D.; da Silva, C. Enzymatic interesterification of crambe oil assisted by ultrasound. Ind. Crops. Prod. 2017, 97, 218-223. [CrossRef]

39. Bhangu, S.K.; Gupta, S.; Ashokkumar, M. Ultrasonic enhancement of lipase-catalysed transesterification for biodiesel synthesis. Ultrason. Sonochem. 2017, 34, 305-309. [CrossRef]

40. Mohod, A.V.; Subudhi, A.S.; Gogate, P.R. Intensification of esterification of non edible oil as sustainable feedstock using cavitational reactors. Ultrason. Sonochem. 2017, 36, 309-318. [CrossRef] [PubMed]

41. Sadaf, S.; Iqbal, J.; Ullah, I.; Bhatti, H.N.; Nouren, S.; Nisar, J.; Iqbal, M. Biodiesel production from waste cooking oil: An efficient technique to convert waste into biodiesel. Sustain. Cities Soc. 2018, 41, 220-226.

42. Charoenchaitrakool, M.; Thienmethangkoon, J. Statistical optimization for biodiesel production from waste frying oil through two-step catalyzed process. Fuel Process. Technol. 2011, 92, 112-118. [CrossRef] 